\title{
ESMERALDA DA MINA DE PITEIRAS, REGIÃO DE ITABIRA, MG: GEOLOGIAE GÊNESE
}

\section{DEIWYS JOSÉ VIANA ${ }^{1}$, HANNA JORDT-EVANGELISTA ${ }^{2} \&$ CAROLINE J. SOUZA GOMES ${ }^{3}$}

\begin{abstract}
Resumo A mina de Piteiras, localizada no distrito esmeraldífero de Itabira-Nova Era, Minas Gerais, foi estudada em termos de geologia, mineralogia e gênese. A mineralização concentra-se num corpo tabular com dois a quatro metros de largura e centenas de metros de extensão composto de xistos metaultramáficos com variáveis teores de flogopita e $\mathrm{Mg}$-hornblenda. O corpo apresenta-se fortemente cisalhado e intrudido por pegmatitos sintectônicos ricos em albita. As encaixantes são paragnaisses pertencentes a uma seqüência metavulcanossedimentar de possível idade arqueana, metamorfizados em condições da fácies anfibolito em temperatura em torno de $600^{\circ} \mathrm{C}$ e pressão de 5,5kbar. Esmeralda é encontrada em flogopita xistos e veios de quartzo nas proximidades dos pegmatitos. Durante um evento tectonometamórfico regional desenvolveu-se um zona de cisalhamento pervasiva numa camada ultramáfica da seqüência metavulcanossedimentar. A deformação concentrou-se preferencialmente nessa camada devido ao contraste reológico. Pegmatitos intrudiram o corpo metaultramáfico durante o cisalhamento e forneceram os fluidos que causaram o processo metassomático que levou à flogopitização e à geração da esmeralda por meio do Be e Si contidos nos fluidos residuais e do cromóforo $\mathrm{Cr}$ dos xistos. A percolação dos fluidos teve controle estrutural.
\end{abstract}

Palavras-chave: Esmeralda, Mina de Piteiras, Itabira, Geologia, Petrogênese

\begin{abstract}
EMERALD FROM THE PITEIRAS MINE, ITABIRA REGION, MG: GEOLOGY AND GENESIS The mine of Piteiras in the emerald district of Itabira-Nova Era, Minas Gerais, was investigated in terms of geology, mineralogy and genesis. The mineralization is concentrated in a two to four meters wide and hundreds of meter long tabular body of metaultramafic schists composed of variable amounts of phlogopite and $\mathrm{Mg}$-hornblende. The body is strongly sheared and was intruded by syntectonic albite-rich pegmatites. The country rocks are paragneisses belonging to a metavulcanossedimentary sequence of possible Archean age, metamorphosed under conditions of the amphibolite facies, at temperatures around $600^{\circ} \mathrm{C}$ and pressures of $5.5 \mathrm{kbar}$. Emerald is found in phlogopite schists and quartz veins in the vicinity of the pegmatites. During a tectono-metamorphic event a pervasive shear zone was developed within an ultramafic layer of the metavulcanossedimentary sequence. Deformation was preferentially concentrated within this layer because of contrasting rheology. Pegmatites intruded the metaultramafic body during shearing and supplied the fluids that caused metassomatic phlogopitization and enabled the crystallization of emerald using the Be and Si from the residual fluids and the cromophore $\mathrm{Cr}$ from the schists. The percolation of fluids was structurally controlled.
\end{abstract}

Keywords: Emerald, Piteiras Mine, Itabira, Geology, Petrogenesis

INTRODUÇÃO Considerada uma das gemas mais importantes no mundo, a esmeralda, variedade de berilo com intensa cor verde, vem sendo explotada em quantidade cada vez maior no estado de Minas Gerais. A região compreendida entre Itabira - Nova Era, em particular, é mundialmente conhecida por duas importantes jazidas: Capocirana e Belmont. Mais recentemente, descobriram-se duas outras nessa região, Piteiras, distante poucos quilômetros das duas outras (Fig. 1) e Rocha, localizada adjacente a Belmont.

A caracterização do controle petrográfico, das estruturas e das condições de temperatura e pressão da mineralização e das encaixantes por geotermobarometria tem como objetivo contribuir para o entendimento da gênese da mineralização esmeraldífera em Piteiras. O estudo de esmeralda em território mineiro se reveste de particular relevância, à medida que o co-nhecimento dos condicionantes geológicos aumenta a chance de se encontrarem novas jazidas.

Os estudos aqui apresentados foram desenvolvidos nas circunvizinhanças, galerias de acesso e dentro da mina, totalizando cerca de 300 metros de seção ao longo do corpo mineralizado. Este é o primeiro trabalho de detalhe desenvolvido no local, o que é particularmente importante em virtude das excelentes exposições das rochas mineralizadas e das encaixantes.

LOCALIZAÇ̃̃O E GEOLOGIA REGIONAL A Província Esmeraldífera de Minas Gerais, onde se encontram as minas Pi-teiras e Belmont, o garimpo de Capoeirana e outras ocorrências, localiza-se entre Itabira e Nova Era (Fig. 1). A região é composta por unidades granito-gnáissicas, metavulcanossedimentares e pegmatitos (Souza 1988 e 1991, Souza et al. 1990, Machado 1998, Machado e Schorscher 1997). As rochas granito-gnáissicas são de diversos tipos: Metagranitóides Borrachudos, Metagranitóides Foliados com Fluorita, Complexo TTG Arqueano e Gnaisses de Derivação Incerta (Machado 1998, Machado e Schorscher 1997). Os Metagranitóides Borrachudos são rochas anorogênicas, de afinidade alcalina, datadas em 1,7 Ga (Dossin et al. 1993) e relacionadas à abertura do rift Espinhaco (Chemale Jr. 1987, Dossin et al. 1993, Fernandes et al. 1995, Dussin et al. 1997). Preinfalk et al. (2002) descreveram e dataram, pelo método $\mathrm{Rb}-\mathrm{Sr}$, dois tipos de pegmatitos para a região. Os mais antigos, presumivelmente ligados ao magmatismo gerador dos Metagranitóides Borrachudos e associados à esmeralda, teriam sido gerados a 1,9 Ga durante o Transamazônico. Os pegmatitos indeformados, interpretados como associados à migmatização do granitóide Borrachudos, são localmente mineralizados em água-marinha e de idade brasiliana, conforme datações de Preinfalk et al. (2002) e outros (Bilal et al. 1995, Marciano et al. 1994).

Da seqüência metavulcanossedimentar (SVS) fazem parte rochas metaultramáficas como os flogopita xistos associados à mineralização esmeraldífera, metamáficas e gnaisses paraderivados. Essa seqüência é considerada como pertencente ao greenstone belt arqueano Rio das Velhas (e.g. Machado 1998, Souza 1988) ou ao Complexo Guanhães (Padilha et al. 2000). Preinfalk et al. 


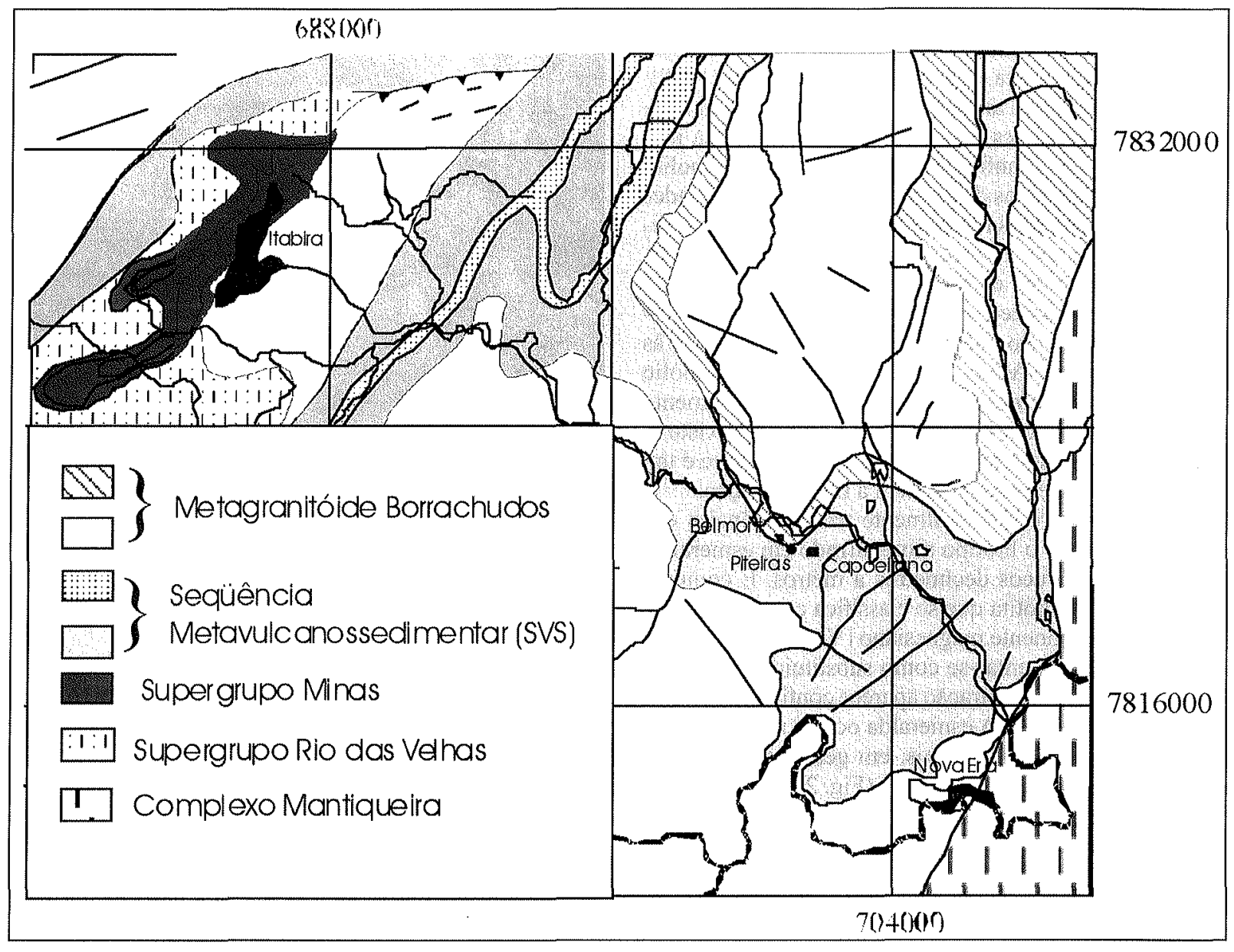

Figura 1 - Mapa geológico simplificado da região da mina de Piteiras (modificado de Machado 1998 e Padilha et al. 2000).

(2002) determinaram idade Rb-Sr de 1,9Ga (idade transama-zônica) para mica, feldspato e rocha total dos gnaisses bandados encaixantes das mineralizações esmeraldíferas da região de Nova Era - Itabira - Ferros, que foi interpretada como sendo também a idade da própria mineralização.

MINA DE PITEIRAS Na área da mina de Piteiras os tipos litológicos principais são paragnaisses, metamáficas e metaultramáficas da Seqüência Metavulcanossedimentar e pegmatitos. A mineralização esmeraldífera concentra-se nas metamáficas/metaultramáficas associadas a pegmatitos. Rochas correlacionadas ao Metagranitóide Borrachudos, encontradas em outras jazidas da região, inexistem em Piteiras.

Encaixantes Gnaisse constitui o litotipo mais abundante na região da Mina de Piteiras. É a encaixante do corpo metamáfico/ metaultramáfico mineralizado, sendo que o contato é abrupto. Nessa unidade ocorrem os seguintes tipos litológicos:

Biotita-granada gnaisse \pm estaurolita \pm sillimanita \pm cianita é o gnaisse mais comum. Ocorre nos arredores da mina e tem sua melhor exposição na rampa de acesso ao corpo mineralizado. É bandado, sendo que as camadas têm em torno de 15 a 20 $\mathrm{cm}$ de espessura. Os principais minerais são biotita, plagioclásio com $\mathrm{An}_{30}$ (Viana, 2004) e quartzo. Microclina só aparece nas bandas de biotita gnaisse. Granada, com a composição média $\mathrm{Alm}_{75} \mathrm{Pir}_{20} \mathrm{Gross}_{4} \mathrm{Esp}_{1}$, chega a $40 \%$ em volume do gnaisse. Estaurolita, sillimanita e cianita são quantitativamente subordinadas. Sillimanita fibrosa aparece preferencialmente nas bordas ou clivagens da biotita. Cianita encontra-se isolada dos demais minerais por envoltório de alteração simplectítica, o que é uma evidência de não pertencer à paragênese principal. A presença de minerais aluminosos como sillimanita, cianita e estaurolita indicam que o gnaisse é derivado de protólito sedimentar pelítico, isto é, trata-se de um paragnaisse.

$\mathrm{Na}$ rampa de acesso à mina ocorrem ainda bandas irregulares de espessura decimétrica de quartzo-plagioclásio-anfibólio fels, também identificado em furos de sondagem. O anfibólio do sistema ortorrômbico é gedrita, aparece decussado e com até $5 \mathrm{~cm}$ de comprimento.

Hornblenda xisto, denominado "anfibolito ultramáfico" por Souza (1988) e Machado (1998), ocorre em corpos lenticulares de porte centimétrico a decimétrico dentro do gnaisse e também do corpo mineralizado. O anfibólio perfaz $95 \%$ em volume da rocha, tendo sido identificado por análise de microssonda como Mg-hornblenda (Viana, 2004). Biotita, plagioclásio, quartzo e minerais opacos são quantitativamente subordinados.

Intercalações de espessura métrica de anfibolito são encontrados tanto no gnaisse quanto no corpo mineralizado. É composto por anfibólio e plagioclásio e, como minerais acessórios, ocorrem quartzo, apatita, ilmenita e pirita. $\mathrm{O}$ anfibólio classifica-se como tschermakita e, localmente, pode apresentar sobrecrescimento do ortoanfibólio antofilita (Viana, 2004). Plagioclásio varia de andesina a labradorita, com teor crescente de Ca do centro para a borda. Às vezes, o anfibolito pode conter granada, nesse caso o plagioclásio é oligoclásio a andesina.

Corpo mineralizado $\mathrm{O}$ corpo mineralizado em esmeralda ocorre como uma "camada" de dois a quatro metros de largura e com centenas de metros de extensão. Localmente, a largura chega a doze metros em virtude de dobramento. A direção do corpo va- 
ria em torno de $\mathrm{N} 30 \mathrm{~W}$, com mergulho de 35 graus para SW.

É composto por metaultramáficas foliadas, denominadas xistos ultramáficos por Souza $(1988,1991)$ e Machado (1998). O principal tipo litológico é anfibólio-biotita xisto, o qual contém intercalações lenticulares de espessura centimétrica a métrica de hornblenda xisto (=anfibolito ultramáfico), de anfibolito e de gnaisses semelhantes aos da encaixante. Nas proximidades dos pegmatitos a biotita passa a predominar e a rocha classifica-se como flogopita xisto. O anfibólio-biotita xisto é composto por proporções variáveis de biotita e anfibólio. Localmente plagioclásio também aparece e a rocha classifica-se como anfibolito. Como acessórios são encontrados quartzo, fluorita e, às vezes, cromita aluminosa (Viana 2004). Dois tipos de anfibólio foram identificados, $\mathrm{Mg}$-hornblenda e actinolita. Com aumento na quantidade de anfibólio a rocha passa a hornblenda xisto e, quando a biotita predomina, tem-se o flogopita xisto, que é um tipo litológico importante porque contém a mineralização.

Flogopita xisto ocorre principalmente nas adjacências dos corpos de pegmatitos e é o litotipo mineralizado em esmeralda. A espessura varia de poucos decímetros a metros. É composto, essencialmente, por biotita que se classifica como flogopita, com 75 a $80 \%$ do componente magnesiano (Viana, 2004). Talco é secundário e pode apresentar-se como substituição de biotita ou anfibólio. Em maior concentração aparece confinado a planos de falha paralelos à foliação. A esmeralda ocorre no xisto e nos veios de quartzo como porfiroblastos, em geral centimétricos. Podem apresentar-se tortos ou fraturados (Fig. 2). Contém cerca de $0,25 \%$ (em peso) de $\mathrm{Cr}_{2} \mathrm{O}_{3}$ e $0,60 \%$ de $\mathrm{FeO}$ (Viana, 2004). $\mathrm{O}$ teor de $\mathrm{V}_{2} \mathrm{O}_{3}$, que também pode ser o elemento cromóforo em esmeralda, é irrisório, abaixo do limite de detecção da microssonda. Portanto, conclui-se que a causa da cor da esmeralda de Piteiras é o $\mathrm{Cr}$, mas o $\mathrm{Fe}$ não está descartado.

Intrusões pegmatíticas ocorrem sob a forma de corpos irregulares alinhados na direção NW-SE (Fig. 3). Apresentam dimensões variáveis, chegando a dezenas de metros. São compostos quase que exclusivamente por albita, localmente possuem quartzo gráfico ou bolsões com moscovita e clinocloro. Berilo é raro e sua cor é azulada. Os pegmatitos são envolvidos pela foliação (Fig. 4) e apresentam-se deformados, com fraturas extensionais perpendiculares à foliação, às vezes preenchidas por quartzo.

$\mathrm{Na}$ mina há veios compostos por quartzo, por feldspato ou por quartzo e feldspato (Fig. 5), com espessura de poucos centímetros a decímetros e concordantes com a foliação principal. Cristais euédricos a subédricos de esmeralda ocorrem dentro de veios de quartzo. Quando dentro de veios feldspáticos os cristais são anédricos, com bordas aparentemente corroídas. Os veios de quartzo ocorrem mais distantes dos pegmatitos e é neles que aparece a esmeralda de melhor cor.

GEOLOGIA ESTRUTURAL As estruturas encontradas em Piteiras, cuja orientação geral pode ser observada na Figura 3, foram geradas em pelo menos três fases de deformação. A mais antiga, $\mathrm{d}_{\mathrm{n}-1}$, foi responsável pela geração do bandamento composicional $S_{n-1}$ da encaixante gnáissica e das metaultramáficas do corpo mineralizado.

A segunda fase, $d_{n}$, resultante de cisalhamento reverso sinistral, conforme descrito por Peres et al. (2004) para a região situada entre Itabira e Ferros, foi responsável pelo desenvolvimento da xistosidade planoaxial de dobras isoclinais da foliação $\mathrm{S}_{\mathrm{n}-1}$. É a principal estrutura planar e possui uma atitude média de 240/30. Localmente, classifica-se como foliação milonítica, associando-se a estruturas S-C. A fase $d_{n}$ pode estar relacionada com o pico do metamorfismo, já que os grãos da paragênese de maior grau nos paragnaisses, estaurolita + sillimanita + biotita + quartzo, e o anfibólio nas metaultramáficas do corpo minera-

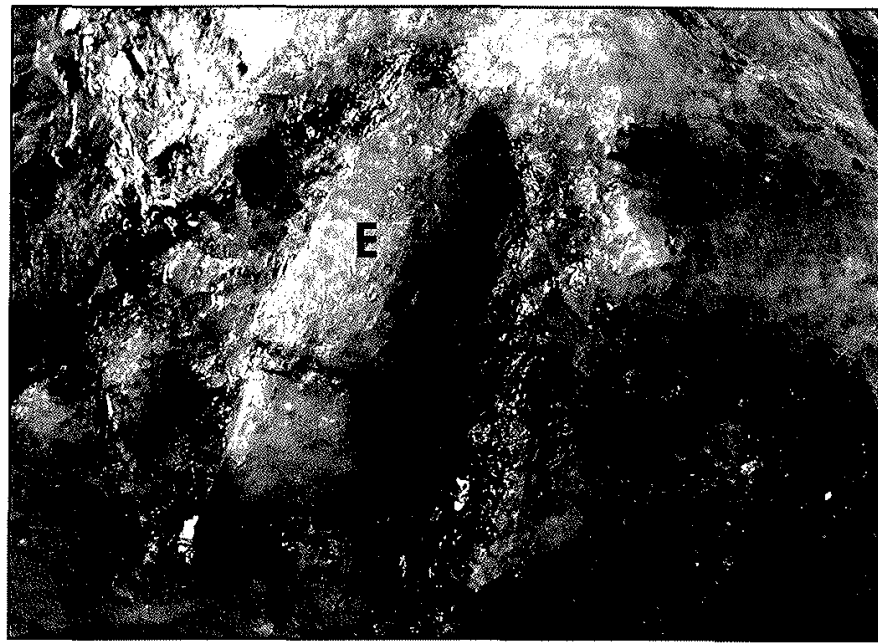

Figura 2-Cristal fraturado de esmeralda $(E)$ medindo cerca de $6 \mathrm{~cm}$ de comprimento

lizado, encontram-se orientados no plano da foliação $S_{n}$, constituindo uma lineação mineral com atitude média 162/35. Provavelmente, a intrusão dos pegmatitos, cujos corpos são alongados em direção aproximadamente coincidente com a da lineação mineral, ocorreu em $\mathrm{d}_{n}$, durante o pico do metamorfismo de fácies anfibolito. A presença de estruturas rúpteis, como falhas e fraturas extensionais, sugere que a intrusão foi sintectônica precoce. A geração da esmeralda também deve ser contemporânea a essa fase, pois a sua formação está ligada à intrusão dos pegmatitos e à instalação da extensa zona de cisalhamento que constitui o corpo mineralizado.

Uma terceira fase de deformação $d_{n+1}$ gerou dobras de pequeno porte, centimétricas, fechadas a isoclinais e uma foliação planoaxial $\mathrm{S}_{n+1}$, com orientação média $315 / 52$.

GEOTERMOBAROMETRIA A determinação das condições de temperatura e pressão em que se formaram as rochas em Piteiras baseou-se nos geotermômetros biotita-granada, hornblenda-plagioclásio, granada-estaurolita e granada-anfibólio e nos geobarômetros GASP e granada-anfibólio-plagioclásio (Viana, 2004). Os resultados foram comparados com aqueles obtidos com auxílio do software TWEEQU, de Berman (1991). Ambos métodos apresentam limitações quanto a sua aplicabilidade. Para a geotermobarometria clássica a dificuldade consiste em se escolher a melhor calibração para um determinado tipo de rocha, pois, para um mesmo par ou paragênese mineral, os resultados podem diferir substancialmente. Os resultados com TWEEQU mostraram-se sensíveis principalmente ao tipo de modelo de mistura adotado e também ao tipo de membros finais utilizados.

Verifica-se que há diferenças nos resultados obtidos para as rochas metapelíticas e as metamáficas, mesmo quando próximas espacialmente. Para as rochas metamáficas ocorre uma "superestimativa" principalmente da temperatura, com valores de até $690^{\circ} \mathrm{C}$ (Viana, 2004). Para as rochas metapelíticas, as temperaturas calculadas pelo método convencional variaram de 505 a $618^{\circ} \mathrm{C}$ e a pressão foi calculada em cerca de $4 \mathrm{kbar}$. Com o TWEEQU as temperaturas obtidas para centro e borda de granada foram de 560 a $580^{\circ} \mathrm{C}$ e pressão em torno de $5,5 \mathrm{kbar}$. Nesse caso, a pressão obtida foi de $1,5 \mathrm{kbar}$ mais alta do que a calculada pelo método convencional. Considerando a paragênese univariante estaurolita + quartzo + granada + sillimanita encontrada nos gnaisses, a sua faixa de estabilidade é de 4,2 a $6,8 \mathrm{kbar}$ e 600 a $690^{\circ} \mathrm{C}$ (Bucher \& Frey 1994, Yardley 1989). Portanto, a pressão em torno de $5,5 \mathrm{kbar}$ obtida pelo TWEEQU, que está 


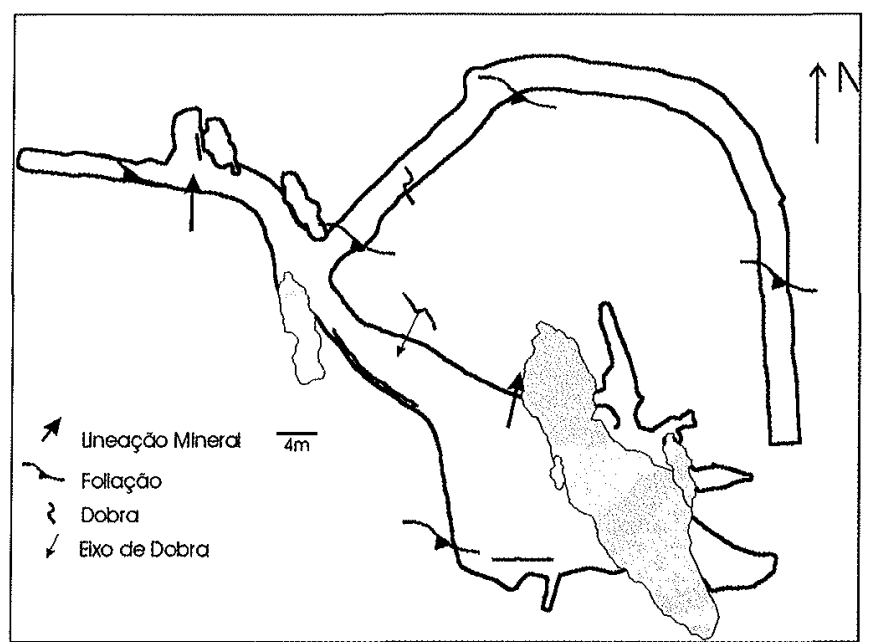

Figura 3-Orientação geral dos principais elementos estruturais e dos pegmatitos (em tonalidade cinza) da Mina de Piteiras.

dentro dessa faixa, é a mais provável para o metamorfismo na área da mina de Piteiras. Em termos de temperaturas, os valores de 560 a $580^{\circ} \mathrm{C}$, obtidos com o TWEEQU, e os de 505 a $618^{\circ} \mathrm{C}$, calculados pela geotermometria convencional são, em média, mais baixos do que os interpretados pela paragênese (entre 600 e $690^{\circ} \mathrm{C}$ ), o que pode ser fruto de reequilíbrio parcial no metamorfismo regressivo. $\mathrm{O}$ valor em torno de $600^{\circ} \mathrm{C}$, portanto, é o mais plausível levando em conta tanto os resultados por cálculos geotermométricos quanto o equilíbrio univariante da paragênese de maior grau. Conclui-se que as rochas em Piteiras foram metamorfizadas na fácies anfibolito, numa pressão em torno de 5,5 kbar e temperaturas em torno de $600^{\circ} \mathrm{C}$.

GÊNESE DA ESMERALDA: DISCUSSÃO E CONCLUSÕES A mineralização esmeraldífera de Piteiras está contida num corpo tabular com espessura média de dois metros e que se estende por centenas de metros, composto por rochas metaultramáficas como anfibólio-biotita xisto e flogopita xisto. $\mathrm{O}$ corpo mineralizado, que está encaixado em paragnaisses de fácies anfibolito, apresenta-se fortemente cisalhado e com intrusões de pegmatitos albíticos. O teor de flogopita na metaultramáfica e a ocorrência de esmeralda aumentam nas proximidades dos pegmatitos, sugerindo que a formação do flogopita xisto e da esmeralda está relacionada a essas intrusões, provavelmente por ação metassomática associada ao cisalhamento. Cromita reliquiar no xisto indica a presença do cromóforo cromo e berilo dentro dos pegmatitos mostra que estes são a fonte de berilo para a formação da esmeralda.

É provável que a mineralização tenha se concentrado em uma camada ultramáfica/máfica de maior espessura do gnaisse. Durante um episódio tectono-metamórfico que atingiu a fácies anfibolito, de idade incerta (Brasiliano? Transamazônico?) desenvolveu-se uma extensa zona de cisalhamento nessa camada de rochas de reologia diferente dos gnaisses. Pegmatitos intrudiram as rochas durante o cisalhamento e forneceram fluidos que causaram transformações metassomáticas nas rochas encaixantes, levando à flogopitização e à geração da esmeralda pela introdução de Be. A percolação dos fluidos através do corpo metamáfico/metaultramáfico foi controlada por estruturas deformacionais como charneiras de dobras, fraturas e/ou pela foliação principal.

O controle da mineralização da mina de Piteiras é litológico e estrutural. Em termos litológicos verifica-se que esmeralda é encontrada em flogopita xisto e veios de quartzo e quartzo-fel-

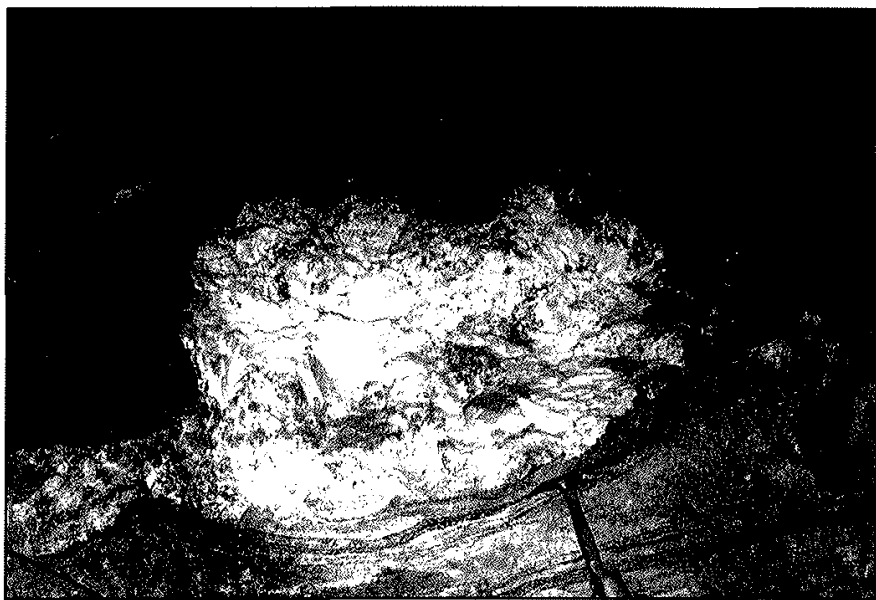

Figura 4 - Pegmatito no contato do corpo mineralizado (acima) com gnaisse (abaixo), envolvido pela foliação. Escala: martelo mede cerca de $30 \mathrm{~cm}$

dspáticos nas adjacências de intrusões de pegmatitos. A esmeralda de melhor cor é aquela encontrada nos veios de quartzo, indicando que os fluidos mais diferenciados, carregando o Be e Si provenientes da cristalização residual dos pegmatitos, tiveram aumentada a capacidade de incorporar o $\mathrm{Cr}$ da encaixante ultramáfica, possivelmente por terem migrado por distâncias maiores dentro da rocha portadora do cromo. A distribuição dos pegmatitos, por sua vez, tem influência estrutural, pois constituem corpos alongados segundo NS, que também é a direção da principal lineação mineral. Além disso, estruturas como foliação milonítica, falhas e charneiras de dobras controlam a distribuição das zonas flogopitizadas bem como dos veios mineralizados, sugerindo que houve percolação de fluidos mineralizantes ao longo de descontinuidades estruturais.

Schwarz e Giuliani (2001) classificam os depósitos mundiais de esmeralda em dois tipos, o tipo I, que são depósitos relacionados com intrusões graníticas, e o tipo II, não relacionado com intrusões graníticas. O primeiro, que é o mais comum em nível mundial, é denominado depósito do tipo xisto, onde se têm pegmatitos cortando rochas máficas/ultramáficas ou sedimentares. Nos depósitos do tipo II estruturas tectônicas, como falhas de empurrão e zonas de cisalhamento, são os controladores da mi-neralização em esmeralda. Verifica-se que, no caso de Piteiras, o depósito tem tanto condicionantes genéticos do tipo I quanto do tipo II. Isso porque a mineralização está associada a xistos com intrusões pegmatíticas (tipo I), mas a intrusão dos pegmatitos e a percolação dos fluidos metassomáticos que levaram à formação do flogopita xisto e da esmeralda foram possibilitadas pela ação de um episódio deformacional que levou à geração da zona de cisalhamento impressa no corpo ultramáfico (tipo II).

Uma particularidade da mina de Piteiras é que lá não foi encontrado o granito Borrachudos, considerado como o progenitor dos pegmatitos da região e que é encontrado em outras jazidas. Isso se reveste de particular importância em pesquisa de novas áreas de ocorrência de esmeralda, pois além de se procurar por regiões de contato entre a seqüência metavulcanossedimentar e o granitóide Borrachudos, pode-se pesquisar também regiões mais afastadas deste contato, conforme é o caso de Piteiras.

Agradecimentos Ao CNPq pela bolsa de mestrado do primeiro autor, à FAPEMIG pelo apoio financeiro (Processo CRA 543/03), ao Laboratório de Microssonda Eletrônica da UFMG pelas análises, à Mina de Piteiras pelo apoio logístico. 


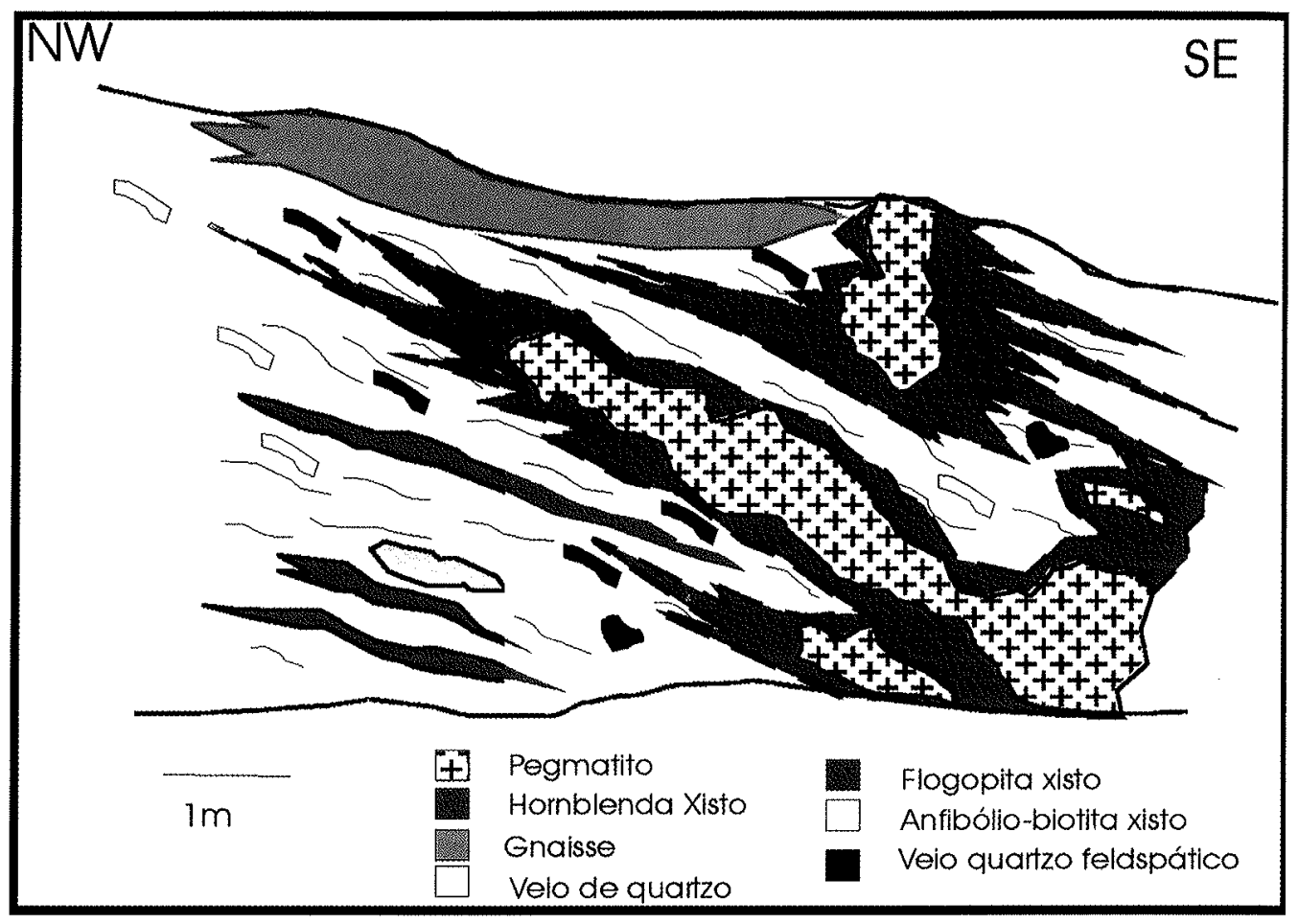

Figura 5 - Localização dos diferentes tipos de mineralização esmeraldifera na Mina de Piteiras: a esmeralda ocorre no flogopita xisto, em veios quartzo-feldspáticos e em veios de quartzo, sendo que esses últimos são os mais distantes do pegmatito e, em geral, possuem a melhor esmeralda.

\section{Referências}

Berman R.G. 1991. Thermobarometry using multiequilibrium calculations: a new technique with petrologic applications. Canadian $\mathrm{Mi}-$ neralogist, 29:833-855.

Bilal E., Marciano V.R.P.R.O., Fuzikawa K., Correia Neves J.M., Giret, A. 1995. Datação de monazitas do Distrito Pegmatítico de Santa Maria de Itabira, MG. In: SBG, Simp. Geol. Minas Gerais, 8, Diamantina, Boletim, v. 13, p.46-47.

Bucher K. \& Frey M. 1993. Petrogenesis of Metamorphic Rocks. Springer, Berlin. 318p.

Chemale Jr. F. 1987. Gênese das rochas graníticas do tipo Borrachudos. In: SBGq, Cong. Bras. Geoquímica, 1, Porto Alegre, Anais, v.1: 171186.

Dussin I.A., Dussin T.M., Charvet J., Cocherie A., Rossi P. 1993. Single-zircon dating by step-wise $\mathrm{Pb}$-evaporation of Middle Proterozoic magmatism in the Espinhaço Range, southeastern São Francisco Craton (Minas Gerais, Brazil). In: SBG, Simp. Cráton São Francisco, 2, Salvador, Anais, p. 39-42

Dussin T. M., Dussin I. A., Noce C. M., Rossi P., Charvet J. 1997. Tectonic setting and origin of the Mesoproterozoic Borrachudos granites (MG, Brazil). In: SBG, South-American Symp. on Isotope Geology, Campos do Jordão, Extended Abstracts, p. 104-106.

Fernandes M.L.S., Marciano V.R.P.R O., Oliveira R.C., Correia Neves J.M., Diláscio M.V. 1995. Granitos Borrachudos: um exemplo de granitogênese anorogênica na porção central do Estado de Minas Gerais. Geonomos, 2:23-29

Grundmam G., Morteani G. 1989. Emerald mineralization during regional metamorphism: The Habachtal (Austria) e Leydsdorp (Transvaal, South Africa) Deposits. Economic Geology, 84:1835-1849.

Machado G.A.A. 1998. Jazidas de Esmeralda de Capoeirana e Belmont - MG: Geologia, petrogênese e metalogênese. Tese de doutoramento, Inst. de Geociências, Universidade de São Paulo, São Paulo, 294 p.

Machado G.A.A., Schorcher H.D. 1997. Geologia da região e aspectos genéticos das jazidas de esmeraldas de Capoeirana e Belmont MG. In: SBG/Núcleo Minas Gerais, Simp. Geol. Minas Gerais. 9, Ouro
Preto, Boletim, 14:47-49.

Marciano V.R.P.R.O., Javier Rios F., Achtschin A.B., Correia Neves J.M., Svisero D.P. 1994. Berilos de pegmatitos de Santa Maria de Itabira, Minas Gerais - Brasil. Geonomos, 2:41-50.

Paditha A.V., Bruno E.M., Vieira V.S. 2000. Folha Itabira, SE.23-Z-DIV: escala I:100.000. Programa Levantamentos Geológicos Básicos do Brasil - PLGB, Projeto Belo Horizonte-Serro. CPRM, Brasília, $71 \mathrm{p}$.

Peres G.G., Alkmim F.F, Jordt-Evangelista, H. 2004 The southern Araçuaí belt and the Dom Silverio Group: geologic architecture and tectonic significance. Anais da Academia Brasileira de Ciências, 76(4):771-790.

Preinfalk C., Kostitsyn Y., Morteani G. 2002. The pegmatites of the Nova Era-Itabira-Ferros pegmatite district and the emerald mineralization of Capoeirana and Belmont (Minas Gerais, Brazil): geochemistry and Rb-Sr dating. J. South American Earth Sciences, 14:867-887.

Schwarz D., Giuliani G. 2001. Emerald deposits - a review. Australian Gemologist, 21:17-23.

Souza J.L. 1988. Geologia e mineralogia da esmeralda da jazida de Itabira, Minas Gerais. Dissertação de mestrado, IG - USP, S. Paulo, 192p.

Souza J.L. 1991. A jazida de esmeralda de Itabira - MG. In: Schobbenhaus et al. (eds.) Principais Depósitos de Minerais do Brasil. Vol 4-A, DNPM, Brasília, pp.: 223-243.

Souza J.L., César-Mendes J., Bello R.M.S., Svisero D., Valarelli J.V. 1990. Estudos petrográficos, mineralógicos e microtermométricos da esmeralda do Garimpo de Capoeirana, Nova Era, Minas Gerais. In: SBG, Cong. Bras. Geologia, 36, Natal, Anais, v. 3, p. 1389-1402

Viana D.J. 2004. Geologia e petrogênese da mina de esmeralda de Piteiras. Dissertação de Mestrado DEGEO/ UFOP, Ouro Preto, 103p.

Yardley B.W.D. 1989. Introdução à petrologia metamórfica. EDUNB, Brasilia, 340p.

Manuscrito A-1531

Revisão aceita em 18 de agosto de 2006 